\title{
Effects of Nozzle Type and Spray Pressure on Control of Alternaria Leaf Blight of Muskmelon with Chlorothalonil
}

\author{
Daniel S. Egel, Extension Plant Pathologist, and Philip Harmon, Graduate Student, Department of Botany and \\ Plant Pathology, Purdue University, Southwest Purdue Agricultural Center, Vincennes, IN 47591
}

\begin{abstract}
Egel, D. S., and Harmon, P. 2001. Effects of nozzle type and spray pressure on control of Alternaria leaf blight of muskmelon with chlorothalonil. Plant Dis. 85:1081-1084.

Methods of fungicide application were evaluated for their influence on the chemical control of Alternaria leaf blight of muskmelon in 1997, 1998, and 1999. Chlorothalonil was applied through either flat-fan or hollow-cone nozzles and with spray pressures ranging from 207 to $1,034 \mathrm{kPa}$. In all 3 years, unsprayed controls had significantly more disease than any of the sprayed treatments. There was no significant effect of nozzle type on disease severity or yield in any year. Spray pressures of 207,414 , or $620 \mathrm{kPa}$ did not significantly affect disease severity or yield in 1997. In 1998, the $827-\mathrm{kPa}$ pressure significantly lowered disease severity compared with the $207-\mathrm{kPa}$ and $414-\mathrm{kPa}$ pressures, but a similar decrease in the number of lesions per leaf did not occur. Yield responses in 1998 did not support a relationship between spray pressures and disease control. In 1999, spray pressure of 1,034 $\mathrm{kPa}$ did not significantly decrease the area under the disease progress curve as estimated from weekly ratings of the disease severity ratings or counts of lesions per leaf made on two dates. Results indicate no differences in disease control due to any of the application methods examined.
\end{abstract}

Additional keywords: Alternaria cucumerina, chemical control, Cucumis melo, fungicide

Commercially acceptable control of many plant diseases is dependent on the use of protective fungicides. The most effective methods of fungicide application are little understood. While popular opinion (Sprayer Technology News, Homestead, FL) holds that diseases of vegetable crops are best controlled by the use of hollow-cone nozzles and high spray pressures, data that support such claims are lacking. Reports on the subject of application technology are quite diverse, but not extensive on any one subject. Ground application resulted in the highest residue of chlorothalonil on potato leaves, followed by aerial application and chemigation (11). Low initial residue levels with chemigation were reduced further after redistribution. Similarly, ground application provided the highest concentrations of chlorothalonil, followed by underslung boom and chemigation, respectively (1). Applying chlorothalonil to potatoes by attached boom provided higher residues of chorothalonil and, therefore, superior disease control compared to application through a center-pivot irrigation system (9). Chemigation diluted the fungicide and,

Corresponding author: D. S. Egel

E-mail: egel@purdue.edu

Accepted for publication 14 June 2001.

Publication no. D-2001-0725-02R

(C) 2001 The American Phytopathological Society thus, resulted in lower residue levels than the attached boom. There was no difference in disease control for early leaf spot or late leaf spot of peanut, bacterial spot of pepper, and blast or purple blotch of onions whether sprayed with hollow-cone or flatfan nozzles (16). Similarly, no difference was observed in the control of early leaf spot or late leaf spot of peanut as a result of spray pressures applied at 50 or 250 psi (15). The optimum spray pressure for coverage of barley and wheat heads with a fluorescent dye varied with nozzle type and arrangement (22). There have been no studies published on the most effective nozzle type and spray pressure for disease control in cucurbits.

Effective methods of fungicide application are of practical importance to vegetable growers. Considerable time and money are spent on fungicide application technology. Spray rigs capable of achieving high spray pressures require special pumps, hoses, and connections. Application of fungicides at high pressures may result in spray drift on nontarget crops. Thus, effective control of vegetable disease at lower spray pressures would prove advantageous.

Integrated pest management (IPM) programs emphasize effective application methods for fungicides and other pesticides. Increasingly, regulatory authorities have encouraged or mandated a decrease in pesticide use. Forecasting systems such as TOMCAST $(10,20)$ and MELCAST (19) may reduce the total number of fungicide applications by demonstrating when such applications are most appropriate based on weather conditions. Thus, adoption of IPM programs has resulted in fewer fungicide applications. Fewer fungicide applications place increased importance on the effectiveness of the remaining applications.

Alternaria leaf blight of muskmelon is a serious threat to muskmelon production in Indiana. The leaves of muskmelon plants can be severely blighted, leading to lower yield (17), reduced sugars (18), or both. No commercial muskmelon cultivar possesses an acceptable level of resistance or tolerance to Alternaria leaf blight $(5,6)$. Thus, a fungicide spray program is necessary to prevent yield loss. The weatherbased disease forecasting system MELCAST (19) has been devised to help growers apply fungicides in a timely manner while often reducing the number of fungicide applications.

The purpose of this study was to determine the most effective spray pressure and nozzle type to efficiently control Alternaria leaf blight of muskmelon. Spray pressures were chosen to minimize the production of droplets less than $100 \mu \mathrm{m}$ in diameter (2000 Catolog 45A: TeeJet; Spraying Systems Co., Wheaton, IL) because smaller droplets increase the chance of drift $(3,8,12)$. Nozzle types tested were either flat fan or hollow cone because these nozzle types are widely available and were identified as those most often used in a grower survey in 1998 (7). A brief report of this research has been previously published (4).

\section{MATERIALS AND METHODS}

Experiments were conducted on the Southwest Purdue Agricultural Center (SWPAC) in Vincennes, IN in 1997, 1998, and 1999. The muskmelon (Cucumis melo L.) cv. Eclipse was seeded in the greenhouse in mid-April prior to transplanting into the field during the first week in May. Transplants were spaced at $76.2 \mathrm{~cm}$ within rows that were on 2.4-m centers. Plots consisted of a row containing 14 plants that was mulched with 2-mil, 1.2-m-wide black plastic (Visqueen 4020, Oxfordshire, UK). Treatment rows were immediately adjacent to a spreader row that was inoculated with a suspension $(10,000$ conidia/ml) of Alternaria cucumerina (Ellis \& Everh.) J. A. Elliot when vines touched within a row. Conidia for inoculum were produced by inoculating V8 juice agar (25) in petri plates with 3-mm-diameter plugs of a cul- 
Table 1. Alternaria leaf blight severity and yield of muskmelons sprayed with chlorothalonil using three spray pressures and two nozzle types (flat fan and hollow cone) in 1997x

\begin{tabular}{lccc}
\hline Spray pressure (kPa) & Disease severity $^{\mathbf{y}}$ & ${\text { Yield }(\mathbf{k g} / \mathbf{h a})^{\mathbf{z}}}^{\mathbf{z}}$ & Yield (no./ha) $^{\mathbf{z}}$ \\
\hline Unsprayed & $11.4 \mathrm{~b}$ & 1,302 & 486 \\
207 & $4.1 \mathrm{a}$ & 1,302 & 502 \\
414 & $3.8 \mathrm{a}$ & 1,597 & 574 \\
620 & $3.6 \mathrm{a}$ & 1,114 & 401 \\
\hline
\end{tabular}

${ }^{x}$ Nozzle type was not significant at $P<0.05$; therefore, spray pressures are shown here across nozzle types.

${ }^{y}$ Percent disease converted from the Horsfall-Barratt rating scale. Values in a column followed by the same letters are not significantly different at $P=0.05$ as determined by Fisher's least significant difference.

${ }^{\mathrm{z}}$ There were no differences in weight or number of fruit harvested at $P=0.05$.

Table 2. Alternaria leaf blight severity and yield of muskmelons sprayed with chlorothalonil using three spray pressures and two nozzle types (flat fan and hollow cone) in $1998^{\mathrm{x}}$

\begin{tabular}{lcccc}
\hline Spray pressure (kPa) & Disease severity $^{\mathbf{y}}$ & Lesions per leaf & Yield (kg/ha) $^{\mathbf{z}}$ & Yield (no./ha) $^{\mathbf{z}}$ \\
\hline Unsprayed & $46.9 \mathrm{c}$ & $4,076 \mathrm{~b}$ & 1,045 & 408 \\
207 & $14.9 \mathrm{~b}$ & $738 \mathrm{a}$ & 1,374 & 520 \\
414 & $13.2 \mathrm{~b}$ & $753 \mathrm{a}$ & 1,107 & 394 \\
827 & $7.3 \mathrm{a}$ & $530 \mathrm{a}$ & 1,268 & 438 \\
\hline
\end{tabular}

${ }^{\mathrm{x}}$ Nozzle type was not significant at $P<0.05$; therefore, spray pressures are shown here across nozzle types.

y Percent disease converted from the Horsfall-Barratt rating scale. Values in a column followed by the same letters are not significantly different at $P=0.05$ as determined by Fisher's least significant difference.

${ }^{\mathrm{z}}$ There were no significant differences at $P=0.05$ in weight or number of fruit harvested.

Table 3. Alternaria leaf blight severity and yield of muskmelons sprayed with chlorothalonil using three spray pressures and two nozzle types (flat-fan and hollow-cone) in $1999^{\mathrm{x}}$

\begin{tabular}{|c|c|c|c|c|c|}
\hline \multirow[b]{2}{*}{ Spray pressure $(\mathbf{k P a})$} & \multicolumn{2}{|c|}{ Lesions per leaf } & \multirow[b]{2}{*}{ AUDPC $^{\mathbf{y}}$} & \multirow[b]{2}{*}{ Yield $(\mathrm{kg} / \mathrm{ha})^{\mathrm{z}}$} & \multirow[b]{2}{*}{ Yield (no./ha) ${ }^{\mathrm{z}}$} \\
\hline & 25 June & 2 July & & & \\
\hline Unsprayed & $2.0 \mathrm{a}$ & $4.0 \mathrm{~b}$ & $494.5 \mathrm{~b}$ & 1,752 & 674 \\
\hline 207 & $1.6 \mathrm{a}$ & $2.1 \mathrm{a}$ & $135.3 \mathrm{a}$ & 1,239 & 506 \\
\hline 620 & $2.5 \mathrm{a}$ & $0.8 \mathrm{a}$ & $112.0 \mathrm{a}$ & 1,616 & 635 \\
\hline 1,034 & $2.2 \mathrm{a}$ & $1.3 \mathrm{a}$ & $113.3 \mathrm{a}$ & 1,773 & 681 \\
\hline
\end{tabular}

$\mathrm{x}$ Nozzle type was not significant at the $\mathrm{P}<0.05$; therefore, spray pressures are shown here across nozzle types. Values in a column followed by the same letters are not significantly different at $P=$ 0.05 as determined by Fisher's least significant difference.

${ }^{y}$ AUDPC $=$ area under the disease progress curve.

${ }^{\mathrm{z}}$ There were no significant differences in weight or number of fruit harvested at $P=0.05$.

ture of A. cucumerina. After approximately 8 days, the plates were flooded with sterile tap water and agitated with a rubber spatula. The concentration of conidia was adjusted to 10,000 conidia/ml using a Spencer hemacytometer before plant inoculation. Bravo Ultrex (chlorothalonil at $2.77 \mathrm{~kg} / \mathrm{ha}$ ) was applied according to the MELCAST weather-based disease forecasting system (19). The initial chlorothalonil application was timed to coincide with vine-touch within a row. All subsequent applications were applied using MELCAST. Following MELCAST recommendations, fungicides are applied every 20 environmental favorability index (EFI) values instead of every 7 to 14 days. Fungicide applications are made every 2 weeks whether the 20 EFI threshold has been reached or not. The first fungicide application followed the field inoculation within $24 \mathrm{~h}$, usually about June 1. All experimental designs were randomized complete blocks with four replications.
A single-row, tractor-mounted, roller pump sprayer was custom built by SWPAC engineers. The sprayer had three booms, each with a different nozzle type that could be interchanged. The spray pressure was regulated between 207 and 1,034 $\mathrm{kPa}$. The model of nozzle type used was varied according to pressure required. Flat-fan TeeJet nozzles 8003VS were used for 207 , 414 , and $620 \mathrm{kPa}(30,60$, and $90 \mathrm{psi})$. Flatfan TeeJet nozzles XR8004 and 80015VS were used for 827 and $1,034 \mathrm{kPa}$ (120 and 150 psi), respectively. Hollow-cone nozzles TeeJet TXVS-12 were used for 207, 414, 620, 827, and 1,034 kPa. Each single-row boom consisted of three nozzles spaced $50.8 \mathrm{~cm}$ apart. To insure that all combinations of spray pressure and nozzle type received the same spray volume, the speed of the John Deere 6410 front wheel assist tractor was calibrated and adjusted for each treatment.

In 1997 and 1998, the plots were visually assessed for severity once during the growing season using the Horsfall-Barratt scale (13) on 4 August and 28 July, respectively. The Horsfall-Barratt rating scale is a $\log _{10}$-based scale used to assign percent foliage affected into one of 11 severity classes. Because it is a log scale, disease severity ratings representing low (e.g., 3 to $6 \%$ infected) and high (e.g., 94 to $97 \%$ infected) severities are of a relatively narrower range of percents than midrange percent classes (e.g., 25 to $50 \%$ infected). In 1999, the plots were assessed on 25 June and $2,10,15,22$, and 29 July. The area under the disease progress curve (AUDPC) was calculated from Horsfall-Barratt values using trapezoidal integration $(17,23)$. In 1998, in addition to the Horsfall-Barratt ratings, the number of lesions per leaf were counted once during the growing season. Three leaves were picked arbitrarily from each plot. The lesion numbers on the three leaves per plot were averaged. In 1999, lesions were counted on 25 June and 2 July using the same method described above, except that lesions were counted only if they occurred at the intersect of lines on a 1-in. grid. Each year yield was taken by counting and weighing marketable fruit from each plot.

Spray patterns were visualized using water-sensitive spray strips that were 57 $\mathrm{cm}$ long and $2.5 \mathrm{~cm}$ wide (Spraying Systems Co.). Spray strips were placed on the horizontal angle of T-shaped wooden stakes. Each stake was $33 \mathrm{~cm}$ high. One stake was placed in each plot. The sprayer described above was driven over the strips while applying water with either flat-fan or hollow-cone nozzles at 207, 414, and 827 $\mathrm{kPa}$. The test was replicated by applying spray on each of three separate days. For quantification of the application coverage by the experimental sprayer, 4-cm sections of the strips were chosen arbitrarily. The percent coverage on the water-sensitive strips was quantified using digital imaging regardless of drop size or placement of drops on the strips. A series of high-resolution (1,000-by-630-pixel) images were made of the selected portions of the watersensitive paper on a flatbed scanner (Saphir, Linotype-Hell, Eschbon, Germany). Image analysis was performed using a Macintosh G4 computer with Mac OS 9.0 operating system running IPLab Scientific Imaging Software (Scanalytics, Inc., Fairfax, VA).

The main effects, nozzle-type, and spray pressure as well as interaction effects of nozzle type by spray pressure were analyzed by analysis of variance (ANOVA). A mean separation test was used on means significantly different at $P=0.05$. Fisher's protected least significant difference at $P=$ 0.05 was used to compare treatment means. When spray pressures were regressed against lesion number per leaf, AUDPC, or percent coverage, control data was excluded because this treatment did not represent a spray pressure. All regressions were tested for lack of fit using the $P$ 
Table 4. Analysis of variance table of 1999 field experiment comparing nozzle types (flat fan versus hollow cone) and spray pressures $(207,620$, and 1,034 kPa)

\begin{tabular}{lrcrrc}
\hline Source & df & Sum of squares & Mean square & F value & $\boldsymbol{P}$ value \\
\hline Nozzle type & 1 & $2,768.238$ & $2,768.238$ & 0.568 & 0.4592 \\
Spray pressure & 3 & $843,590.704$ & $281,196.901$ & 57.746 & 0.0001 \\
Nozzle $\times$ spray pressure & 3 & $13,289.426$ & $4,429.809$ & 0.910 & 0.4531 \\
Block & 3 & $26,682.017$ & $8,894.006$ & 1.826 & 0.1733 \\
Residual & 21 & $102,260.364$ & $4,869.541$ & $\ldots$ & $\ldots$ \\
\hline
\end{tabular}

value. Statistical analysis was done using SuperAnova (Abacus Concepts, Inc., Berkeley, CA).

\section{RESULTS}

Each year, artificial inoculation of the spreader rows with $A$. cucumerina resulted in disease that spread into the treatment rows. Increased rainfall in 1998 resulted in more disease and greater Horsfall-Barratt ratings than in either 1997 or 1999 (Tables 1, 2, and 3). In 1999, lesions caused by $A$. cucumerina were observed by 25 June, 2 weeks after inoculation. On 25 June, lesions covered a range of 0 to $3 \%$ of the foliage. By 22 July, lesions covered a range of 3 to $75 \%$ of the foliage.

Nozzle type did not significantly affect disease severity in any one of the three trails. Therefore, spray pressures were examined across nozzle types. ANOVA tables were similar for 1997, 1998, and 1999. The ANOVA table for 1999 is shown in Table 4.

In 1997, there was no significant difference among any of the nozzle type-spray pressure combinations. The unsprayed control had significantly more disease, as measured by the Horsfall-Barratt rating scale, than any of the spray pressure treatments (Table 1). No yield differences were observed. In 1998, there was no significant difference in disease severity for muskmelons sprayed with fungicides at 207 and 414 $\mathrm{kPa}$, but plots sprayed at $827 \mathrm{kPa}$ had significantly lower disease severity than any other treatment (Table 2). Lesion number did not differ between any of the spray pressure treatments. Differences in disease severity observed in the 1998 experiment did not affect total number or weight of muskmelons harvested (Table 2). Regression of Horsfall-Barratt ratings against spray pressure (without control data) yielded $R^{2}=0.36, P$ value $=0.002$. Lesion number regressed against spray pressure (without control data) yielded $R^{2}=0.18, P$ value $=0.039$. Image analysis of watersensitive spray strips did not reveal significant differences in the percent of coverage with either flat-fan or hollow-cone nozzle types or 207,414 , and $827 \mathrm{kPa}$ spray pressure (Table 5). There was not a linear relationship between percent coverage and spray pressure $\left(P=0.2468, R^{2}=0.083\right)$.

In 1999, the AUDPC did not differ among spray pressure treatments (Table 3). There was no significant difference in lesion numbers on 25 June but, on 2 July, leaves from control plots had significantly more lesions than those from treated plots (Table 3). No other significant differences were observed. There was not a significant linear relationship between AUDPC and spray pressures (excluding controls; $P$ value $=0.3956$ ). There was also no significant linear relationship between lesion number and spray pressure on either date (excluding controls; data not shown). There were no yield differences in 1999 (Table 3).

\section{DISCUSSION}

The nozzle types and spray pressures used here to apply chorothalonil did not have a significant effect on control of Alternaria leaf blight of muskmelon. These results were consistent during all 3 years of field testing. No difference in disease severity was observed as a result of either nozzle type or any spray pressure used. foliage covered as a result of the nozzles or spray pressure used.

Spray pressure did not affect disease severity except as measured by the HorsfallBarratt ratings in 1998. In the same year, there was not a significant effect on lesions per leaf over the same spray pressures. The data from 1999 did not indicate a difference in control of Alternaria leaf blight with spray pressures that ranged from 207 to $1,034 \mathrm{kPa}$. The latter data are more robust than the 1998 data because seasonlong severity data were collected in 1999 and used to calculate AUDPC. In all 3 years, unsprayed plants were more severely diseased than any of the sprayed plants.

Literature pertaining to the control of plant diseases often emphasizes "good coverage" (21,24). Exactly what constitutes good coverage and how to achieve that coverage is uncertain. Hollow-cone nozzles are usually used to apply fungicides to plants $(2,14,21)$. Hollow-cone nozzles provide better overall coverage while flat-fan nozzles provide deeper coverage into the plant canopy (21). This study supports the conclusions of others $(15,16)$ that have found little difference in nozzle type and spray pressure in disease control.

Optimum nozzle type and spray pressure may depend on individual pathosystems. Wheat has a plant canopy much different than muskmelon. Wheat heads are vertical, whereas muskmelon leaves are, for the most part, horizontal. The optimum spray pressure for coverage of barley and wheat was greatest with a nozzle arrangement Nor was there any difference in percent
Table 5. Percent coverage of water-sensitive strips sprayed with either flat-fan or hollowcone nozzles and spray pressures of 207, 414, and $827 \mathrm{kPa}$ with a three-point hitch, one row tractor sprayer $^{\mathrm{y}}$

\begin{tabular}{lcc}
\hline Nozzle type & $\begin{array}{c}\text { Spray } \\
\text { pressure (kPa) }\end{array}$ & $\begin{array}{c}\text { Percent } \\
\text { coverage }^{\mathbf{z}}\end{array}$ \\
\cline { 1 - 2 } Flat fan & 207 & 58.1 \\
Flat fan & 414 & 48.8 \\
Flat fan & 827 & 64.7 \\
Hollow cone & 207 & 49.7 \\
Hollow cone & 414 & 43.8 \\
Hollow-cone & 827 & 59.2
\end{tabular}

$\mathrm{y}$ The three nozzles were spaced $50.8 \mathrm{~cm}$ inches apart and all strips were sprayed at 187 liters/ha.

z No significant differences were observed with Fisher's least significant difference means comparison at $P=0.05$.

that directed the spray downward at an angle rather than vertically (22).

Muskmelon growers using chlorothalonil can effectively manage Alternaria leaf blight by choosing either flat-fan or hollow-cone nozzles and spray pressures ranging from 207 to $1,034 \mathrm{kPa}$. This study indicates that muskmelon growers need not purchase sprayers capable of high spray pressures. Fungicides applied under high pressures may result in unwanted drift. Nozzle types may be chosen based on grower preference. In addition, extension programs may emphasize the timing of fungicide applications and choice of chemicals over how those fungicides should be applied.

The plant part affected by disease may also influence the optimum spray application techniques. Alternaria leaf blight affects only leaves; a disease such as gummy stem blight that affects stems and fruit as well may require different fungicide application techniques. Finally, application conditions such as gallonage, different nozzle types, and adjuvant may affect disease control.

\section{ACKNOWLEDGMENTS}

We thank D. Nowaskie for building the singlerow sprayer and R. Martyn and G. Shaner for providing critical comments. This work was supported in part by a grant from the North Central Pesticide Impact Assessment Program.

\section{LITERATURE CITED}

1. Brenneman, T. B., Sumner, H. R., and Harrison, G. W. 1990. Deposition and retention of chlorothalonil applied to peanut foliage: Effects of application methods, fungicide formulations and oil additives. Peanut Sci. $17: 80-84$

2. Byass, J. B. 1979. The application of pesticides. Section 2.1 to 2.29 in: Pest and Disease Control Handbook, British Crop Protection Council, Croydon, Great Britain.

3. Courshee, R. J. 1967. Application and use of foliar fungicides. Pages 239-285 in: Fungicides: An Advanced Treatise. D. C. Torgeson, ed. Academic Press, London and New York.

4. Egel, D. S. 1998. Using spray pressure and nozzle type to apply chlorothalonil efficiently to muskmelons infected with Alternaria leaf blight. (Abstr.) Phytopathology 88:S25. 
5. Egel, D. S. 1999. Severity of Alternaria leaf blight on muskmelon varieties, 1996. Biol. Cult. Tests 14:157

6. Egel, D. S. 1999. Severity of Alternaria leaf blight on muskmelon varieties, 1997. Biol. Cult. Tests $14: 158$

7. Egel, D. S. 1999. Benefit Analysis of a single use fungicide for Muskmelons in Indiana. Purdue University, SWP-1.

8. Finney, J. R. 1995. Comparing glasshouse and field pesticide performance. Pestic. Sci. 44:205-206.

9. Geary, B, Johnson, D. A., Hamm, P. B., and Cummins, T. F. 1999. Fungicide applications for late blight management: a boom attached to a center pivot irrigation system. Plant Dis. 83:512-515.

10. Gleason, M., MacNab, A., Pitblado, R., Ricker, M., East, D., and Latin, R. 1995. Disease-warning systems for processing tomatoes in Eastern North America: Are we there yet? Plant Dis. 79:113-121.

11. Hamm, P. B., and Clough, G. H. 1999. Comparison of application methods on deposition and redistribution of chlorothalonil in a potato canopy and potential control of late blight.
Plant Dis. 83:441-444.

12. Hislop, E. C. 1987. Can we define and achieve optimum pesticide deposits? Asp. Appl. Biol. 14:153-172

13. Horsfall, J. G., and Barratt, R. W. 1945. An improved grading system for measuring plant diseases. (Abstr.) Phytopathology 35:655.

14. Johnson, M., and Swetnam, L. 2001. Sprayer Nozzles: Selection and Calibration. University of Kentucky, PAT-3, Lexington.

15. Kucharek, T., Riabov, J., and Cromwell, R. 1981. The effect of spray volume and spray pressure on peanut leafspot control. Pages 6474 in: Proc. Fla. Conf. Pestic. Appl. Technol.

16. Kucharek, T. A., Cullen, R. E., Stall R. E., and Llewellyn, B. 1986. Chemical control of foliar diseases of peanut, peppers, and onions as affected by spray nozzle types, nozzle orientations, spray intervals, and adjuvants. Plant Dis. 70:583-586.

17. Latin, R. 1992. Modeling the relationship between Alternaria leaf blight and yield loss in muskmelon. Plant Dis. 76:1013-1017.

18. Latin, R., Rane, K. K., and Evans, K. J. 1994. Effect of Alternaria leaf blight on soluble solid content of muskmelon. Plant Dis.
78:979-982.

19. Latin, R. X., and Evans, K. J. 1996. Development and delivery of a forecaster for Alternaria leaf blight of muskmelon. (Abstr.) Phytopathology 86:S106

20. Madden. L., Pennypacker, S., and MacNab, A. 1978. FAST, a forecast system for Alternaria solani on tomato. Phytopathology. 68:1354-1358.

21. Matthews, G. A. 2000. Pesticide Application Methods. 3rd ed. Blackwell Science, Inc., London. Malden, MA.

22. McMullen, M., Halley, S., Pederson, J., Hofman, V., Moos, J., Panigrahi, S., Gu, D., and Gregoire, T. 1999. Improved Fungicide Spraying for wheat/barley head scab control. N. D. State Univ. Ext. Rep. 56.

23. Shaner, G., and Finney, R. E. The effect of nitrogen fertilization on the expression of slow-mildewing resistance in Knox wheat Phytopathology 67:1051-1056.

24. Sherf A., and McNabb, A. 1986. Vegetable Diseases and Their Control. 2nd ed. Wiley-Interscience, New York.

25. Tuite, J. 1969. Plant Pathological Methods: Fungi and Bacteria. Burgess Publishing Co. Minneapolis, MN. 